\title{
ASSOCIATION BETWEEN METABOLIC SYNDROME AND HEPATITIS B VIRUS INFECTION \\ IN THE ROMA POPULATION IN EASTERN SLOVAKIA: A POPULATION-BASED STUDY
}

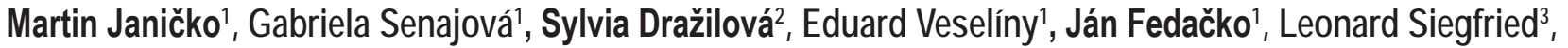 \\ Pavol Kristian ${ }^{4}$, Ladislav Virág ${ }^{4}$, Daniel Pella ${ }^{1}$, Mária Mareková ${ }^{5}$, Andrea Madarasová Gecková6, ${ }^{6}$, Peter Kalaninn, \\ Peter Jarčuška ${ }^{1}$, Monika Halánová9; HepaMeta Team* \\ ${ }^{11}$ st Department of Internal Medicine, P. J. Šafárik University in Košice, Faculty of Medicine and L. Pasteur University Hospital, Košice, Slovakia \\ ${ }^{2}$ Department of Internal Medicine, Poprad Hospital, Poprad, Slovakia \\ ${ }^{3}$ Department of Medical Microbiology, P. J. Šafárik University in Košice, Faculty of Medicine and L. Pasteur University Hospital, Košice, Slovakia \\ ${ }^{4}$ Department of Infectious Diseases, P. J. Šafárik University in Košice, Faculty of Medicine and L. Pasteur University Hospital, Košice, Slovakia \\ ${ }^{5}$ Department of Medical and Clinical Biochemistry, P. J. Šafárik University in Košice, Faculty of Medicine and L. Pasteur University Hospital, \\ Košice, Slovakia \\ ${ }^{6}$ Health Psychology Unit, Department of Public Health, Faculty of Medicine, P. J. Šafárik University in Košice, Košice, Slovakia \\ ${ }^{7}$ Department of Family Medicine, P. J. Šafárik University in Košice, Faculty of Medicine and L. Pasteur University Hospital, Košice, Slovakia \\ ${ }^{8}$ Olomouc University Social Health Institute, Palacký University in Olomouc, Olomouc, Czech Republic \\ ${ }^{9}$ Department of Public Health, Faculty of Medicine, P. J. Šafárik University in Košice, Košice, Slovakia
}

\section{SUMMARY}

Background: The simultaneous presence of chronic hepatitis B (CHB) and metabolic syndrome (MS) in the high-risk Roma community constitutes a high risk for liver cirrhosis and potentially hepatocellular carcinoma. This study aims to explore the relationship between MS and CHB.

Methods: Data from the cross-sectional HepaMeta Study conducted in Slovakia in 2011 among Roma living in rural communities were used. Participants were tested for the presence of MS, and lipid levels - total cholesterol, high density lipoproteins (HDL), low density lipoproteins (LDL), triglycerides (TG), apolipoprotein B100, and CHB HBsAg and anti-HBc IgG were also monitored. Viral load was measured in HBsAg-positive patients.

Results: A total of 452 patients were screened; MS was diagnosed in $29.6 \%$ of patients, and $12.5 \%$ had CHB. Anti-HBc IgG antibodies were present in $52.8 \%$ of patients. CHB patients had lower levels of total cholesterol ( $5.45 \pm 1.21 \mathrm{vs}$. $4.71 \pm 1.23 \mathrm{mmol} / ; ; p=0.035)$, LDL cholesterol (median $2.2 \mathrm{mmol} / /$, interquartile range $0.88 \mathrm{mmo} / / \mathrm{vs} .2 .5 \mathrm{mmo} / /$, interquartile range $0.9 \mathrm{mmol} / / ; p=0.01$ ) and apolipoprotein B100 (median 0.66 $\mathrm{mmol} / /$, interquartile range $0.26 \mathrm{mmo} / / \mathrm{vs} .0 .74 \mathrm{mmol} / /$, interquartile range $0.29 \mathrm{mmo} / / ; p=0.025)$. Patients diagnosed with $\mathrm{MS}$ had a higher HBV DNA load than patients without MS $(1,728.2 \pm 14.33 \mathrm{IU} / \mathrm{ml}$ vs. $12,779.1 \pm 20.9 \mathrm{IU} / \mathrm{ml} ; p=0.037)$. CHB patients with TC and apolipoprotein B100 within the reference range had a lower hepatitis B DNA (HBV DNA) load than patients with high or low values of TC or apolipoprotein B100.

Conclusion: The prevalence of chronic hepatitis B and simultaneous presence of MS was high among Roma. HBsAg-positive patients had lower levels of total and LDL cholesterol along with decreased apolipoprotein B100. The viral load of chronic hepatitis B patients with MS was higher than in patients without MS.

Key words: metabolic syndrome, chronic hepatitis B, cholesterol, apolipoprotein B100, HBV DNA

Address for correspondence: Peter Jarčuška, 1st Department of Internal Medicine, P. J. Šafárik University in Košice, Faculty of Medicine and L. Pasteur University Hospital, Tr. SNP 1, 04011 Košice, Slovakia. E-mail: petjarc@yahoo.com

\section{INTRODUCTION}

Many studies have linked socioeconomic status with metabolic syndrome (MS). Available data shows that people with lower socioeconomic status have a higher risk of developing MS (1-3). Patients with MS have a high risk not only for cardiovascular disease or diabetes mellitus but also for liver disease. According to current knowledge, non-alcoholic steatohepatitis is considered to be a hepatic manifestation of MS. In obese patients (BMI > 30

\footnotetext{
*HepaMeta Team members are listed in Appendix
}

$\mathrm{kg} / \mathrm{m}^{2}$ ) the prevalence of nonalcoholic fatty liver disease (NAFLD) is estimated to be as high as $75 \%$. NAFLD could on its own cause the progression to liver cirrhosis in about $0.5 \%$ of patients (4).

Chronic hepatitis B infection is also strongly associated with socioeconomic status $(5,6)$. Because of the relatively high rate of chronic persisting course, this infection leads to fibrogenesis, cirrhosis and eventually hepatocellular carcinoma (HCC). Patients with HBV DNA load $>10^{5} \mathrm{IU} / \mathrm{ml}$ have a 5 -times higher risk of developing liver cirrhosis than patients with HBV DNA load $\leq 10^{4} / \mathrm{ml}(7)$.

The simultaneous presence of both diseases constitutes an even higher risk for liver cirrhosis and potentially for HCC (8). 
Unfortunately, there is not enough data about the epidemiology of metabolic syndrome in CHB patients in general and even less so for the high-risk population. Roma in Slovakia are a minority with worse health and lower socioeconomic status compared with the majority population (9); as a result, they are the most vulnerable to both CHB and metabolic syndrome. Therefore, this study was aimed to explore the prevalence of metabolic syndrome or partial clinical and laboratory signs in CHB patients. At the same time we tried to assess the influence of metabolic syndrome on viral load and overall disease activity in HBV-infected patients.

\section{MATERIALS AND METHODS}

Data from the cross-sectional HepaMeta study conducted in Slovakia in 2011 were used. This project aimed to map the prevalence of viral hepatitis B/C and MS in the population living in the eastern part of Slovakia, including Roma settlements. In addition to the general methodology described in detail elsewhere (10) further paper-specific amendments to the methodology follow.

Only Roma participants $(n=452)$ were included in this analysis. Participants were considered to have active HBV infection if they were HBsAg positive. Patients with anti-HBc IgG or antiHBsAg positivity were considered to have had encountered $\mathrm{HBV}$ in the past or were vaccinated.

\section{Statistical Analysis}

Results are presented as the median (interquartile range) for continuous variables with nonparametric distribution, or mean \pm standard deviation for data with parametric distribution and percentages for categorical variables, unless stated otherwise. Because of severely skewed baseline distribution in a positive direction, we applied log10 transformation before the analysis of serum cholesterol, HBV DNA, aspartate aminotransferase (AST), alanine aminotranferase (ALT) and gamma-glutamyl transferase (GGT). These variables are presented as geometric mean \pm geometric standard deviation. Differences between the two groups of participants were tested using the student's t-test or the MannWhitney U-test based on the distribution of individual variables. The chi-square test was utilised for categorical variables. The association of MS and individual components of MS with HBV infection was tested using univariate logistic regression adjusted for confounders. The association of individual components of MS with HBV DNA load was assessed by quadratic regression.

\section{RESULTS}

A total of 452 Roma were screened, 10 of them were excluded because of missing vital data. Thus, a total of 442 patients were included (mean age $=34.7 ; \mathrm{SD}=9.1 ; 35.2 \%$ men). Additional patients were excluded because of missing data per analysis, it is indicated by the total number of included patients in the respective Tables.

\section{Factors Associated with Chronic Hepatitis B}

MS was diagnosed in 131 (29.6\%) patients and HBV infection - HBsAg positivity in 55 (12.4\%) patients. Anti-HBc IgG antibodies were present in 233 (52.8\%) patients. Parameters in the study cohort are summarised in Table 1.

Patients with CHB (HBsAg positive) had statistically significant lower levels of total and LDL cholesterol and apolipoprotein B100. No difference was found in HDL, TG, glucose, BMI and waist circumference or in the prevalence of MS, obesity or being overweight. Patients who had encountered HBV (anti-HBc IgG positive) had statistically significant lower levels of HDL along with higher levels of TG, BMI and waist circumference as well as a higher prevalence of obesity or being overweight.

Table 1. Comparison of selected parameters between participants with and without serological markers of HBV infection

\begin{tabular}{|l|c|c|c|c|c|c|}
\hline & HBsAg positive & HBsAg negative & p value & $\begin{array}{c}\text { Anti-HBc lgG } \\
\text { positive }\end{array}$ & $\begin{array}{c}\text { Anti-HBc IgG } \\
\text { negative }\end{array}$ & p value \\
\hline Age (years) & $32.5(12.17)$ & $35.5(15.5)$ & 0.864 & $37.7(11.98)$ & $30.7(16.12)$ & $<0.0001$ \\
\hline Cholesterol (mmol/l) & $4.45 \pm 1.21$ & $4.71 \pm 1.23$ & 0.035 & $4.76 \pm 1.22$ & $4.58 \pm 1.25$ & 0.054 \\
\hline LDL (mmol/l) & $2.2(0.88)$ & $2.5(0.9)$ & 0.010 & $2.5(0.84)$ & $2.4(0.92)$ & 0.139 \\
\hline HDL (mmol/l) & $1.1(0.53)$ & $1.1(0.36)$ & 0.382 & $1.0(0.41)$ & $1.1(0.31)$ & 0.048 \\
\hline TG (mmol/) & $1.02 \pm 1.56$ & $1.15 \pm 1.75$ & 0.130 & $1.2 \pm 1.74$ & $1.06 \pm 1.7$ & 0.048 \\
\hline ApoB100 (g/l) & $0.66(0.26)$ & $0.74(0.29)$ & 0.025 & $0.76(0.29)$ & $0.72(0.3)$ & 0.099 \\
\hline Uric acid (umol/l) & $206.1(99.9)$ & $212.6(103.2)$ & 0.854 & $223.9(98.1)$ & $200.7(105.0)$ & 0.073 \\
\hline Glucose (mmol/l) & $4.6(0.63)$ & $4.7(0.73)$ & 0.477 & $4.7(0.73)$ & $4.6(0.82)$ & 0.115 \\
\hline BMl (kg/m²) & $26(6.72)$ & $25.6(8.75)$ & 0.486 & $26.6(8.64)$ & $24.9(8.8)$ & 0.026 \\
\hline Waist circumference (cm) & $86(16)$ & $88(22)$ & 0.669 & $89(21)$ & $87(20)$ & 0.009 \\
\hline BMl > 30 kg/m² (\%) & 16.4 & 27.4 & 0.802 & 27.0 & 24 & 0.626 \\
\hline BMl > 25 kg/m² $(\%)$ & 50.9 & 52.7 & 0.669 & 56.7 & 47.6 & 0.057 \\
\hline Metabolic syndrome prevalence (\%) & 27.8 & 29.6 & 0.785 & 31.9 & 26.7 & 0.237 \\
\hline SBP (mmHg) & $122.67(18)$ & $119(20)$ & 0.370 & $120(22)$ & $118.67(20)$ & 0.01 \\
\hline dBP (mmHg) & $71.33(16)$ & $73(14)$ & 0.912 & $74(16)$ & $72(14)$ & 0.092 \\
\hline
\end{tabular}

Data presented as the median (interquartile range) for variables with non-normal distribution, mean \pm SD for variables with normal distribution and percentages for categorical variables 
Factors associated with chronic HBV infection were assessed through series of univariate logistic regression models; the results are summarised in Table 2. Only LDL cholesterol was significantly associated with hepatitis B infection, even after adjustment for age, sex and BMI. No association with chronic hepatitis B was found for total cholesterol, apolipoprotein B100 and HDL cholesterol. Furthermore, clinical parameters (BMI and waist circumference) or the presence of metabolic syndrome were not found to be significantly associated with chronic hepatitis B after adjustment for age and sex.

\section{Viral Load in HBsAg-positive Patients}

Out of 55 HBsAg-positive patients, 50 were also HBV DNA positive (90\%). Viral load ranged from 40 to 5,340,000 IU/ml, with a mean viral load of 2,48,317.54 IU/ml, a median of 2,540 $\mathrm{IU} / \mathrm{ml}$, and an interquartile range of $9605 \mathrm{IU} / \mathrm{ml}$. Patients diagnosed with MS had significantly higher HBV DNA load (after $\log 10$ transformation) than patients without MS - a geometric mean of $1,728.2 \pm 14.33$ vs. $12,779.1 \pm 20.9 ; p=0.037$ (Fig. 1). This difference was independent of the age of the HBV DNApositive patients.

HBV DNA association with individual criteria of MS was assessed by the quadratic regression model. This model was chosen instead of linear regression because of the typical distribution of selected parameters (lipid profile, BMI, waist circumference)

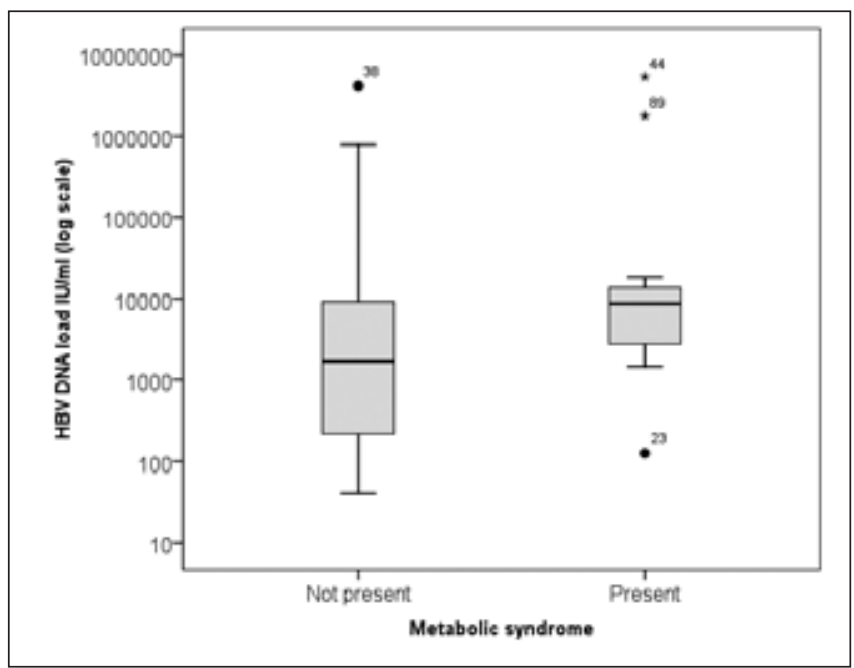

Fig. 1. HBV DNA levels in patients with and without metabolic syndrome. with pathological values at both extremes of the parameter range. Results are summarised in Table 3.

Cholesterol and apolipoprotein B100 had a significant quadratic relationship with HBV DNA (Fig. 2 and 3); other parameters of lipid profile were statistically and marginally insignificant. No relationship between HBV DNA and BMI, waist circumference or mean arterial pressure was found.

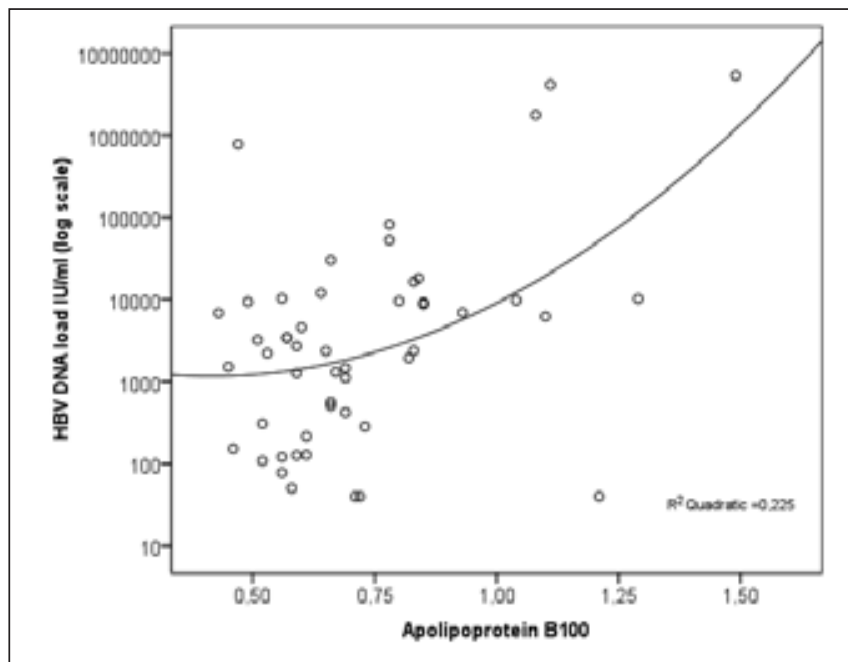

Fig. 2. Association between apolipoprotein B100 and HBV DNA load.

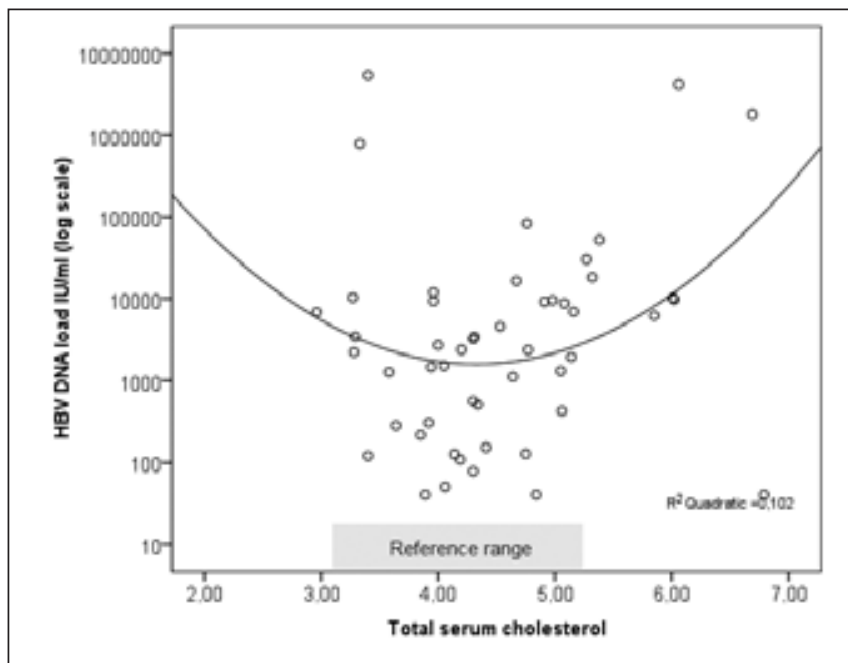

Fig. 3. Association between total cholesterol and HBV DNA load.

Table 2. Association of MS and individual parameters of MS with CHB infection, assessed by logistic regression, adjusted for age, sex and BMI

\begin{tabular}{|l|c|c|c|}
\hline Factor & Adjusted OR & $95 \%$ Cl & p value \\
\hline Cholesterol & 10.67 & $0.394-289.056$ & 0.160 \\
\hline LDL & 1.683 & $1.036-2.735$ & 0.036 \\
\hline TG & 3.659 & $0.757-17.671$ & 0.106 \\
\hline HDL & 0.365 & $0.119-1.122$ & 0.078 \\
\hline ApoB100 & 2.827 & $0.64-12.498$ & 0.171 \\
\hline Waist circumference & 1.014 & $0.991-1.037$ & 0.235 \\
\hline BMI & 1.029 & $0.976-1.084$ & 0.290 \\
\hline Metabolic syndrome & 0.81 & $0.354-1.854$ & 0.618 \\
\hline
\end{tabular}


Table 3. Association between HBV DNA and serum lipidogram, assessed by quadratic regression

\begin{tabular}{|l|c|c|c|}
\hline Independent variable & $\mathbf{R}^{2}$ & Formula & $\mathrm{p}$ value \\
\hline Cholesterol & 0.139 & $-59.411 \mathrm{~h}^{2}+47.34 \mathrm{~h}+21.742$ & 0.029 \\
\hline HDL & 0.046 & $4.12 \mathrm{~h}^{2}-2.029 \mathrm{~h}+1.577$ & 0.331 \\
\hline LDL & 0.072 & $-1.862 \mathrm{~h}^{2}+0.449 \mathrm{~h}+5.191$ & 0.173 \\
\hline TG & 0.101 & $-0.132 \mathrm{~h}^{2}+8.168 \mathrm{~h}+3.162$ & 0.083 \\
\hline Apolipoprotein B100 & 0.225 & $-2.157 \mathrm{~h}^{2}+2.605 \mathrm{~h}+3.511$ & 0.001 \\
\hline
\end{tabular}

$\mathrm{h}$-value of the independent variable

Table 4. Liver transaminases levels in CHB patients with and without metabolic syndrome

\begin{tabular}{|l|c|c|c|}
\hline & Without metabolic syndrome & Metabolic syndrome & $p$ value \\
\hline ALT & $0.25 \pm 2.31$ & $0.38 \pm 2.05$ & 0.008 \\
\hline AST & $0.35 \pm 2.01$ & $0.39 \pm 2.01$ & 0.134 \\
\hline GGT & $0.37 \pm 2.37$ & $0.48 \pm 1.42$ & 0.019 \\
\hline
\end{tabular}

p-value measured by the Mann-Whitney U-test, data presented as the geometric mean \pm geometric SD

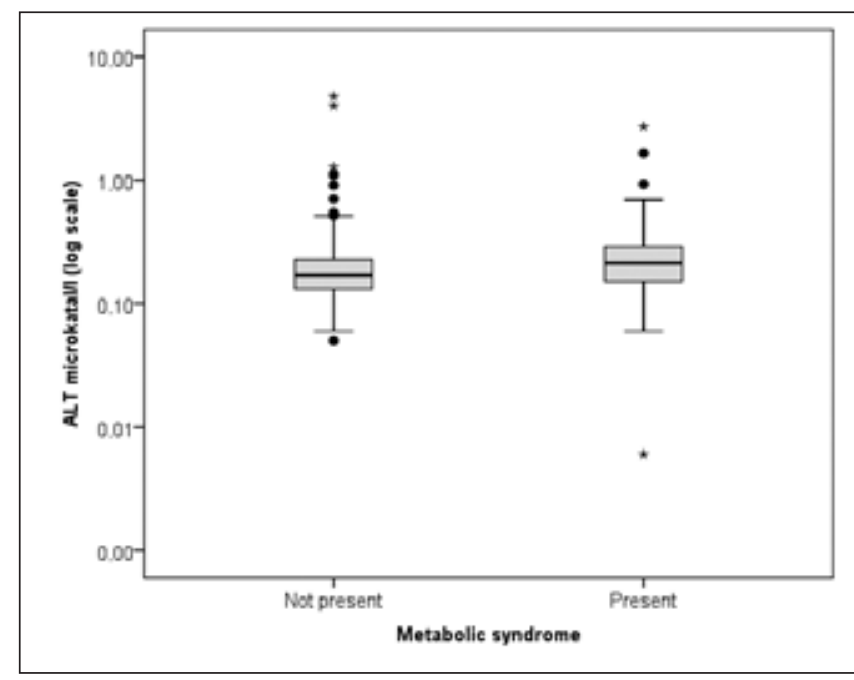

Fig. 4. ALT levels in HBsAg-positive patients with and without MS.

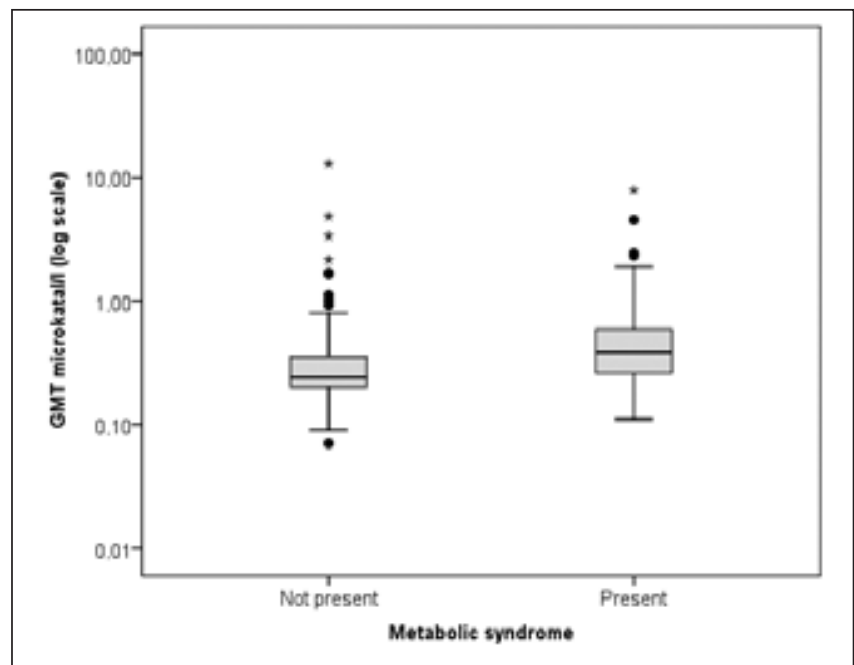

Fig. 5. GGT levels in HBsAg-positive patients with and without MS.

\section{Chronic Viral Hepatitis B Activity}

Hepatitis B activity is usually reflected by serum activity of transaminases. Therefore, we have compared serum levels of ALT, AST or GGT in HBsAg-positive patients with MS compared with those without MS (Table 4). We have found that HBsAg-positive patients with MS had significantly higher levels of ALT and GGT than patients without MS. There was no significant difference in serum levels of AST between these two groups of patients.

\section{DISCUSSION}

The prevalence of HBsAg positivity in the study cohort of Roma was $12.4 \%$. The general prevalence of HBsAg positivity in Slovakia is estimated to be under 1\% (11). No data is available specifically for Slovak Roma, and very little data is available for HBsAg prevalence in Roma communities in the European Union. The prevalence of HBsAg positivity in Roma children in Athens, Greece, is reported to be 4\% (12).

The prevalence of MS in Roma with chronic hepatitis B (HBsAg positive) was not significantly different from the prevalence in HBsAg-negative Roma participants. This was also confirmed for BMI, waist circumference, glycemia HDL, and TG levels.

The prevalence of MS in a cohort of $153 \mathrm{HBV}$-infected patients with a mean age of $50.5 \pm 27.5$ years from the USA was $13 \%$. Furthermore, 40\% of patients had BMI between 27.5-30, 10\% had BMI over 30, and 13\% had diabetes mellitus. Liver histology revealed that $19 \%$ of patients had signs of NAFLD and $13 \%$ had NASH. Patients with metabolic syndrome were older (52 vs. 43 years, $\mathrm{p}=0.05$ ) and had a higher BMI (26 vs. $23 \mathrm{~kg} / \mathrm{m}^{2}, \mathrm{p}=0.05$ ). Although CHB patients with diabetes were more likely to have nonalcoholic steatohepatitis (NASH) (20\% vs. 12\%), this difference was not statistically significant. HBV patients with signs of NAFLD in liver histology were more obese (BMI: 26 in NAFLD $\mathrm{kg} / \mathrm{m}^{2}$ vs. $\left.24 \mathrm{~kg} / \mathrm{m}^{2}, \mathrm{p}=0.02\right)$ and had greater waist circumferences ( $89 \mathrm{~cm}$ and $92 \mathrm{~cm}$, respectively, vs. $83 \mathrm{~cm}, \mathrm{p}=0.03$ ). The presence of superimposed NASH was associated with older age (55 vs. 42 years, $\mathrm{p}=0.008$ ), greater BMI (28 vs. $24 \mathrm{~kg} / \mathrm{m}^{2}$, $\mathrm{p}=0.006$ ), the presence of hypertension ( $63 \%$ vs. $14 \%, \mathrm{p}=0.006$ ) 
and dyslipidemia ( $50 \%$ vs. $7 \%, \mathrm{p}=0.006$ ). The authors conclude that chronic hepatitis B is frequently associated with NAFLD or NASH, primarily in older and obese patients (13).

HBsAg-positive patients had significantly lower levels of TC, LDL and apolipoprotein B100. This association was significant even after adjustment for age, sex and BMI. Similar data has been published relatively often in recent studies, although, to the best of our knowledge, this is the first study reporting apolipoprotein B100. Luo et al. reported that patients with chronic hepatitis B also had a lower level of serum triglycerides, as in this cohort, but that there was also a lower incidence of metabolic syndrome, which this study did not confirm (14). This difference was probably caused by the lower mean age of the patients in this cohort with lower prevalence of metabolic syndrome. Another study reports that HBsAg-positive patients had lower TG, LDL and HDL levels and higher adiponectin levels significantly more often. Total cholesterol level was also lower, albeit only in non-diabetic and non-obese HBsAg-positive patients (15).

The reason behind the lower levels of TC, LDL and apolipoprotein B100 in HBsAg-positive patients remains unclear. Only a small amount of published data allows for the speculation that hepatitis $B$ virus influences the metabolism of infected hepatocyte (16).

In this study cohort 233 (52.8\%) patients had come in contact with viral hepatitis B and formed anti-HBc IgG antibodies. These patients were older, had significantly lower HDL and higher TG values as well as higher BMI and waist circumference. Total serum cholesterol and LDL levels were approximately the same in both groups. A study published by Yen et al. reports that students (mean age 19 years) who overcame acute hepatitis B infection and were anti-HBc positive had a 58\% increased risk of MS compared with vaccinated students with protective titers of anti-HBs antibodies (17). The mechanism behind this observation is not completely clear, however, in this cohort age explains the observed differences sufficiently. Published data suggest that older patients more often meet MS criteria, specifically clinical criteria such as high blood pressure or central obesity (18). In this cohort HBcIgG-positive participants were older and had higher BMI, waist circumference and blood pressure.

Liver tests (ALT, AST, GGT) reflect liver damage caused by any disease. We have found that HBsAg-positive patients who have MS have significantly higher levels of ALT and GGT than HBsAg-positive patients without MS. This is assumingly important finding, as it suggests an additive effect of MS on the liver damage caused by hepatitis B. In the study by Wang et al. the authors report that BMI over 25 and hyperglycemia are independent predictors of ALT elevation in HbsAg-positive patients, even in the upper half of normal range (19).

The second aim of this study was to assess the influence of MS and individual components of metabolic syndrome on HBV DNA levels. It proved that CHB patients with metabolic syndrome have significantly higher levels of HBV DNA. Furthermore, TC and apolipoprotein B100 had a significant quadratic relationship with HBV DNA. Quadratic regression models a relationship between two variables according to a curve similar to the letter U. Patients with cholesterol levels below as well as above the reference range had significantly higher HBV DNA load than patients with serum cholesterol within the reference range. The same is true for apolipoprotein B100. There is more than one possible explanation, although none has yet been confirmed. As discussed earlier, hepatitis B infection interferes with hepatocyte metabolism. A high viral load in particular could cause decreased cholesterol synthesis. Lower TC levels are even associated with a higher incidence of hepatocellular carcinoma in CHB patients (20). Patients with elevated levels of TC or apolipoprotein B100 have a higher viral load than patients with normal cholesterol or apolipoprotein B100. ApoB 100 is the main protein component of LDL and is produced only in the liver. Therefore, it better reflects the metabolism of lipoproteins in the hepatocyte because of the lower potential for confounding factors (diet, obesity, non-fasting serum). Although there has been no data linking viral load in CHB patients with apolipoprotein B100, thus far there are some indices suggesting that either lower or higher levels of lipoproteins are associated with high viral load. In a previously cited study by Hsu et al., the authors described an inverse linear correlation between HBV DNA and TG, but no significant linear correlation was found between HBV DNA and TC, HDL or LDL. Unfortunately, the authors did not analyse any associations other than linear associations (15). A high viral load in CHB patients is a significant risk factor for liver cirrhosis and hepatocellular carcinoma; therefore, this information is important in the management of these patients.

The presence of metabolic syndrome or its components has a negative effect on the natural course of chronic hepatitis B infection. In a study from Hong Kong, histological liver cirrhosis was more common among patients who had MS (38\%) versus those who did not $(11 \%, \mathrm{p}<0.001)$. The prevalence of cirrhosis increased with the number of MS components present (21). Patients with chronic hepatitis B and HCC had significantly higher mean BMI and serum glucose, but lower serum lipids levels than controls $(\mathrm{p}<0.05)$. In a subanalysis of the HCC cohort, the authors reported a significant positive correlation between BMI, insulin and homeostasis model assessment for insulin resistance (HOMA-IR) $(\mathrm{p}<0.01)(21)$. Data from the NHANES III cohort suggest that type 2 diabetes mellitus and/or insulin resistance are independent mortality predictors in CHB patients (22).

The presented study is one of the first reporting the relationship between MS and CHB in the non-Asian population. Also, this study brings new data about the relationship of apolipoprotein B100 and viral load in CHB patients. Unfortunately, there are several limitations. The cross-sectional design of the study did not allow effective follow-up of the patients. Furthermore, it included only patients younger than 45 years, and the incidence of metabolic syndrome is higher in older patients. In addition, there was no assessment of liver fibrosis either histologically, biochemically or with transient elastography. Because no biopsy data were available, we were not able to determine the presence of liver steatosis or steatohepatitis.

\section{CONCLUSION}

Patients with CHB had significantly lower levels of TC, LDL and apolipoprotein B100 compared with HBsAg-negative patients. This is, to the best of our knowledge, the first study reporting lower levels of apolipoprotein B100 in CHB patients. CHB patients with MS had a significantly higher HBV DNA load than CHB patients without MS. Patients with TC and apolipoprotein B100, within the reference range, had lower HBV DNA than patients with hypocholesterolemia or hypercholesterolemia. 


\section{Acknowledgement}

This work was partially supported by the Agency of the Slovak Ministry of Education for the Structural Funds of EU, CEMIO-ITMS: 26220120058 (30\%); the VEGA project, grant 1/1072/12; a grant from Visegrad fund, and Roche Slovakia, s. r. o. This paper was also partially funded within the framework of the project "Social determinants of health in socially and physically disadvantaged and other groups of population" (CZ.1.07/2.3.00/20.0063).

\section{Conflict of Interests}

None declared

\section{APPENDIX}

HepaMeta Team: Peter Jarčuška, Andrea Madarasová Gecková, Mária Mareková, Daniel Pella, Leonard Siegfried, Pavol Jarčuška, Lýdia Pastvová, Ján Fedačko, Jana Kollárová, Peter Kolarčik, Daniela Bobáková, Zuzana Veselská, Ingrid Babinská, Sylvia Dražilová, Jaroslav Rosenberger, Ivan Schréter, Pavol Kristian, Eduard Veselíny, Martin Janičko, Ladislav Virág, Anna Birková, Marta Kmet’ová, Monika Halánová, Darina Petrášová, Katarína Cáriková, Viera Lovayová, Lucia Merkovská, Lucia Jedličková, Ivana Valková

\section{REFERENCES}

1. Dallongeville J, Cottel D, Ferrières J, Arveiler D, Bingham A, Ruidavets $\mathrm{JB}$, et al. Household income is associated with the risk of metabolic syndrome in a sex-specific manner. Diabetes Care. 2005 Feb;28(2):409-15.

2. Manuck SB, Phillips JE, Gianaros PJ, Flory JD, Muldoon MF. Subjective socioeconomic status and presence of the metabolic syndrome in midlife community volunteers. Psychosom Med. 2010 Jan;72(1):35-45.

3. Park MJ, Yun KE, Lee GE, Cho HJ, Park HS. A cross-sectional study of socioeconomic status and the metabolic syndrome in Korean adults. Ann Epidemiol. 2007 Apr;17(4):320-6.

4. Preiss D, Sattar N. Non-alcoholic fatty liver disease: an overview of prevalence, diagnosis, pathogenesis and treatment considerations. Clin Sci (Lond). 2008 Sep;115(5):141-50.

5. Pasquini P, Kahn HA, Pileggi D, Panà A, Terzi J, Guzzanti E. Prevalence of hepatitis B markers in Italy. Am J Epidemiol. 1983 Nov;118(5):699709 .

6. Zhang H, Li Q, Sun J, Wang C, Gu Q, Feng X, et al. Seroprevalence and risk factors for hepatitis B infection in an adult population in Northeast China. Int J Med Sci. 2011;8(4):321-31.

7. Chen CJ, Yang HI, Su J, Jen CL, You SL, Lu SN, et al.; REVEAL-HBV Study Group. Risk of hepatocellular carcinoma across a biological gradi- ent of serum hepatitis B virus DNA level. JAMA. 2006 Jan 4;295(1):6573.

8. Wong GLH, Wong VWS, Choi PCL, Chan AWH, Chim AML, Yiu KKL, et al. Metabolic syndrome increases the risk of liver cirrhosis in chronic hepatitis B. Gut. 2009 Jan;58(1):111-7.

9. Babinska I, Dankulincova Veselska Z, Bobakova D, Pella D, Panico S, Reijneveld SA, et al.; HEPA-META team. Is the cardiovascular risk profile of people living in Roma settlements worse in comparison with the majority population in Slovakia? Int J Public Health. 2013 Jun;58(3):417-25.

10. Madarasová Gecková A, Jarčuška P, Mareková M, Pella D, Siegfried L, Jarčuška P, et al.; HepaMeta Team. HepaMeta - Prevalence of hepatitis $\mathrm{B} / \mathrm{C}$ and metabolic syndrome in population living in separated and segregated Roma settlements: a methodology for a cross-sectional populationbased study using community-based approach. Cent Eur J Public Health. 2014 Mar;22 Suppl:S6-11.

11. Nardone A, Anastassopoulou CG, Theeten H, Kriz B, Davidkin I, Thierfelder W, et al. A comparison of hepatitis B seroepidemiology in ten European countries. Epidemiol Infect. 2009 Jul;137(7):961-9.

12. Michos A, Terzidis A, Kalampoki V, Pantelakis K, Spanos T, Petridou ET. Seroprevalence and risk factors for hepatitis A, B, and C among Roma and non-Roma children in a deprived area of Athens, Greece. J Med Virol. 2008 May;80(5):791-7.

13. Bondini S, Kallman J, Wheeler A, Prakash S, Gramlich T, Jondle DM, et al. Impact of non-alcoholic fatty liver disease on chronic hepatitis B. Liver Int. 2007 Jun;27(5):607-11.

14. Luo B, Wang Y, Wang K. Association of metabolic syndrome and hepatitis B infection in a Chinese population. Clin Chim Acta. 2007 May 1;380(12):238-40.

15. Hsu CS, Liu CH, Wang CC, Tseng TC, Liu CJ, Chen CL, et al. Impact of hepatitis $\mathrm{B}$ virus infection on metabolic profiles and modifying factors. J Viral Hepat. 2012 Feb;19(2):e48-57.

16. Hajjou M, Norel R, Carver R, Marion P, Cullen J, Rogler LE, et al. cDNA microarray analysis of HBV transgenic mouse liver identifies genes in lipid biosynthetic and growth control pathways affected by HBV. J Med Virol. 2005 Sep;77(1):57-65.

17. Yen SL, Chiu TY, Lin YC, Lee YC, Lee LT, Huang KC. Obesity and hepatitis B infection are associated with increased risk of metabolic syndrome in university freshmen. Int J Obes (Lond). 2008 Mar;32(3):474-80.

18. Sun SS, Sabo R, Arslanian S, Wu R, Sabo C. Age variation and sexual dimorphism in the sixteen diagnostic clusters of risk factors for the metabolic syndrome. Z Gesundh Wiss. 2012 Oct;20(5):487-97.

19. Wang YY, Lin SY, Sheu WH, Liu PH, Tung KC. Obesity and diabetic hyperglycemia were associated with serum alanine aminotransferase activity in patients with hepatitis B infection. Metabolism. 2010 Apr;59(4):486-91.

20. Kumada T, Toyoda H, Kiriyama S, Sone Y, Tanikawa M, Hisanaga Y, et al. Incidence of hepatocellular carcinoma in patients with chronic hepatitis $B$ virus infection who have normal alanine aminotransferase values. J Med Virol. 2010 Apr;82(4):539-45.

21. Zhao J, Zhao Y, Wang H, Gu X, Ji J, Gao C. Association between metabolic abnormalities and HBV related hepatocelluar carcinoma in Chinese: a cross-sectional study. Nutr J. 2011 May 15;10:49.

22. Stepanova M, Rafiq N, Younossi ZM. Components of metabolic syndrome are independent predictors of mortality in patients with chronic liver disease: a population-based study. Gut. 2010 Oct;59(10):1410-5. 